\title{
A gênese dos cursos técnicos integrados ao ensino médio dos Institutos Federais de Educação, Ciência e Tecnologia
}

\author{
Lonne Ribeiro Araújo ${ }^{1}$ \\ Josania Lima Portela Carvalhêdo
}

\section{RESUMO}

O presente artigo objetiva descrever o processo histórico dos cursos técnicos integrados ao ensino médio dos Institutos Federais de Educação, Ciência e Tecnologia (IFES), numa perspectiva de projeto societário de inclusão social e emancipação do sujeito, a partir da pesquisa bibliográfica aliada a pesquisa documental. Iniciamos com a história da educação profissional no Brasil, passando pela identificação dos princípios constituintes do projeto de integração dos cursos dos IFES e, em seguida, a relação entre a atual reforma do ensino médio e a proposta dos cursos integrados dessas instituições. Constatamos um processo de transformações educacionais caracterizado por avanços e retrocessos, preso à dualidade estrutural firmada historicamente no país e alimentado pelo modo de produção capitalista, sendo a mais recente reforma do ensino médio, fortalecedora do sistema dual de ensino no país.

Palavras-chave: Educação Profissional. Ensino Médio. Curso Integrado.

\section{The genesis of technical courses integrated to the high school of Federal Institutes of Education Science and Technology}

\section{ABSTRACT}

This article aims to describe the historical process of technical courses integrated to high school from the Federal Institutes of Education, Science and Technology (IFES), in a perspective of a social project of social inclusion and emancipation of the subject, based on bibliographic

1 Mestra em Educação pela Universidade Federal do Piauí - UFPI. Professora do Instituto Federal do Piauí - IFPI. E-mail: Ionne.araujo@ifpi.edu.br.

2 Doutora em Educação pela Universidade Federal do Ceará - UFC. Professora do Departamento de Métodos e Técnicas de Ensino - DMTE e do Programa de Pós-Graduação em Educação PPGEd da Universidade Federal do Piauí. E-mail: josaniaportela@ufpi.edu.br 
research combined with documentary research. We started with the history of professional education in Brazil, going through the identification of the constituent principles of the IFES courses integration project and, then, the relationship between the current reform of high school and the proposal of the integrated courses of these institutions. We found a process of educational changes characterized by advances and setbacks, tied to the structural duality historically established in the country and fed by the capitalist production method, the most recent reform of high school, strengthening the dual system of education in the country.

Keywords: Professional Education. High school. Integrated Course.

\section{La génesis de los cursos técnicos integrados a la enseñanza media de los Institutos Federales de Educación, Ciencia y Tecnología}

\section{RESUMEN}

El presente artículo tiene como objetivo describir el proceso histórico de los cursos técnicos integrados a la enseñanza media de los Institutos Federales de Educación, Ciencia y Tecnología (IFES), en una perspectiva de proyecto societario de inclusión social y emancipación del sujeto, desde la investigación bibliográfica aliada a la investigación documental. Iniciamos con la historia de la educación profesional en Brasil, pasando por la identificación de los principios constituyentes del proyecto de integración de los cursos de los IFES y, en seguida, la relación entre la actual reforma de la enseñanza media y la propuesta de los cursos integrados de dichas instituciones. Constatamos un proceso de transformaciones educacionales caracterizado por avances y retrocesos, preso a la dualidad estructural sujetada históricamente en el país y alimentado por el modo de producción capitalista, siendo la más reciente reforma de la enseñanza media, fortalecedora del sistema dual de enseñanza en el país.

Palabras-clave: Educación profesional. Enseñanza media. Curso Integrado

\section{Introdução}

Os cursos técnicos integrados ao ensino médio no Brasil (EMI) dos Institutos Federais de Educação Ciência e Tecnologia (IFES) constituem-se, pois, como um projeto oriundo de vários debates no entorno 
da educação profissional, no intuito de superar a dualidade estrutural na educação brasileira reproduzida ao longo da história, de forma a possibilitar uma ampla formação do sujeito, superando crenças educativas promovedoras da fragmentação do conhecimento e da dualidade na educação, produzidas pelo modo de produção social no Brasil.

No âmbito do contexto social brasileiro, o estudo objetiva descrever o processo histórico dos cursos técnicos integrados ao ensino médio dos Institutos Federais de Educação Ciência e Tecnologia - IFES numa perspectiva de projeto societário de inclusão social e emancipação do sujeito, a partir da análise dos acontecimentos que influenciaram as transformações na educação profissional (EP) no Brasil, relatado na literatura educacional e nos documentos oficiais.

Assim, a fim de fomentar reflexões acerca dos princípios constituintes dos cursos técnico integrados dos IFES, considerando as determinações históricas, sociais, políticas e econômicas e seu papel na emancipação do sujeito, com base na pesquisa qualitativa dos tipos bibliográfica e documental, apoiados em Oliveira (2012), organizamos este artigo em três seções: na introdução apresentamos o objetivo do estudo, tipo de abordagem e de pesquisa e a organização do artigo; o tópico dedicado ao percurso histórico da educação profissional no Brasil, com seus respectivos subtópicos, em que, por uma travessia cronológica, apresentamos momentos considerados relevantes na formatação dessa modalidade de ensino, envolvendo aspectos sociais ligados, principalmente, à política e economia numa relação dialética inerente a cada contexto e período histórico; e, por último, as considerações finais.

\section{O percurso histórico da educação profissional no Brasil}

O Ensino Médio Integrado surge com base no movimento histórico educacional que fundamentou inicialmente o Ensino Profissional, no qual são reveladas as relações entre a economia, política, cultura e suas modificações tomadas em uma ampla dimensão, ou seja, as diferentes características dos modos de produção no Brasil, dado um tempo e um momento.

Sobre esse argumento, Frigotto (2009) diz ser inerente a história da humanidade, nos mais diferentes modos de produção, desde o mais primitivo ao atual, o envolvimento da 
[...] tríade constituída por uma base material (econômico-social), por dimensões supra-estruturais vinculadas a valores ideologias, ideias, teorias, emoções e por instituições que consolidam, produzem e reproduzem as relações sociais. (FRIGOTTO, 2009, p.129)

Esse argumento nos leva a assumir como pressuposto que, as transformações na educação, em específico os princípios de construção do Ensino Profissional, devem ser interpretados e compreendidos levando em conta que a educação sempre se encontrou abraçada pelo modo de produção social, o que justifica a concreta ligação entre educação e as diversas dimensões da vida humana, sendo o trabalho uma dessas dimensões

No Brasil, essa relação se deu constantemente em uma sociedade marcada pela divisão de classes e regida pelos interesses que ligava Estado ao poder econômico, ou seja, em acordo com Kuenzer (2007), o desenvolvimento das forças produtivas deixava evidente a separação entre capital e trabalho. Desse modo, o processo de formação dos trabaIhadores e cidadãos no Brasil percorreu todo seu trajeto histórico, amparado na dualidade estrutural e apoiado por uma base discriminatória, na medida em que se determinava e se distinguia o caminho educacional daqueles que se destinavam às funções intelectuais dos que iriam exercer funções instrumentais.

Assim, essa estrutura dual de ensino se fez presente desde a sociedade rural oligárquica, característica do Brasil Colônia e esteve diretamente ligada às relações escravistas de produção, dada a predominância da mão-de-obra de negros africanos e índios nativos, influenciando, segundo Manfredi (2002) diretamente na atribuição de valores aos tipos de trabalho (manual ou intelectual). O preconceito se fez tão arraigado, que o exercício de algumas atividades manuais e o ensino destas, passou a ser associado à condição de pobreza e/ou de mendicância, ou "pior", à condição de escravo. Sobre esse fato, Cunha (2005) destaca que, desde o início do Brasil Colônia, havia o afastamento da força de trabalho dos homens livres do artesanato e da manufatura, em razão do emprego da mão-de-obra escrava neste tipo de trabalho.

Condicionado à sua natureza, os benefícios sociais gerados pelo trabalho se mostravam distintos e, em se tratando especificamente do trabalho manual, esses benefícios perpetuamente se constituíam excludentes, fazendo com que os processos educativos ligados à edu- 
cação profissionalizante também se apropriassem de características discriminatórias. Tais características eram facilmente identificadas nas políticas educacionais surgidas ao longo dos anos, colocando o ensino profissional à margem de toda e qualquer ação do Estado até o final do século XIX e começo do século XX, pois nesse período se inicia a transição da sociedade rural oligárquica para uma sociedade urbano-industrial.

Explicamos a ênfase nesse recorte histórico por se tratar de um momento que se esboçou um lento avanço no processo de industrialização, fazendo com que as políticas educacionais se voltassem para atender ao novo sistema que emergia desse processo, o capitalismo. Desse posto, todas as medidas educacionais foram direcionadas para reorganização o modo de produção social no Brasil, de maneira que a geração de riquezas, nesse contexto, passou a priorizar a manutenção hegemônica da classe burguesa.

Assim, no ano de 1909, mediante o interesse de suprir as demandas capitalistas, constatamos pela primeira vez por parte do Estado, uma concreta preocupação em relação à formação do trabalhador, comprovada através da criação das Escolas de Aprendizes e Artífices, pelo então presidente do Brasil, Nilo Peçanha, por intermédio do Ministério da Agricultura, Indústria e Comércio, sendo estas destinadas ao ensino profissional primário gratuito. Ainda no ano de 1909, através do Decreto no. 7.566 (BRASIL, 1909), uma dessas escolas foi instalada em cada capital dos Estados da Republica, com a justificativa de que o aumento populacional das cidades exigia mais possibilidades às classes mais baixas de superar das dificuldades crescentes na luta pela existência e que havia necessidade de habilitar os filhos dos desfavorecidos, com preparo técnico e intelectual, a fim de adquirir hábitos de trabalho e afastar do vício e do crime. Para tanto, Kuenzer (2007, p. 27) explica que a proposta atendia a uma finalidade moral de repressão, "[...] na perspectiva moralizadora da formação do caráter pelo trabalho".

Essa "perspectiva moralizadora" de educação profissional voltada aos desvalidos e apoiada por políticas públicas, esteve atrelada ao projeto de formação do trabalhador até meados da década de 1930, quando a economia, que tinha uma base agroexportadora, entra em declínio em consequência da crise provocada pela queda da bolsa de valores em Nova York no ano 1929, deixando o Brasil de exportar o café para os EUA, seu principal comprador. 
Observado o então cenário, nas décadas de 1930 e 1940, quando Getúlio Vargas assume como presidente do país, as políticas de desenvolvimento econômico priorizaram o fortalecimento da indústria e do comércio, acarretando, concomitantemente, uma maior urbanização. Segundo Nascimento (2007), nesse instante, devido à demanda por mão de obra qualificada, cresce também a necessidade por uma formação mais completa e inclinada para o tipo de trabalho inerente ao novo modelo econômico, fazendo com que as escolas, que eram destinadas à formação profissional, tivessem, de fato, uma relação concreta e direta com a economia, distanciando-se cada vez mais do carater assistencialista do esino profissionalizante.

Nesse contexto, é promulgada a Constituição Federal de 1937 (BRASIL, 1937), em que, pela primeira vez, o ensino técnico profissional e industrial foi tratado em um documento legal no País. Nesse documento, mais precisamente no seu art. 129, percebemos que a educação profissional tem como objetivo preparar o cidadão para operar tecnicamente as máquinas, apontando para a concepção do governo da necessidade de associar essa modalidade educacional à economia e ao mercado de trabalho. No art.132 da lei, podemos ler que o ensino profissional se dava através do "adestramento físico de trabalhadores", nos conduzindo ao entendimento de que essa modalidade de educação se caracterizava pela ideia de trabalho técnico manual destinado àqueles que precisavam apenas executar o saber fazer técnico, ou seja, a educação profissional estava associada à classe subalterna. (BRASIL,1937).

Concernente ao exposto, Frigotto (2003), mediante as questões relacionadas à formação dos trabalhadores no país, a partir das décadas de 1930 e 1940, afirma que o caminho dessa formação se dava na perspectiva de habilitá-los técnica e ideologicamente para o trabalho, limitando e reconstruindo a função social da educação, ao tempo que o ensino profissional era reforçado pela divisão social e técnica do trabaIho e determinado pelas forças produtivas da época, já que a prioridade eram as demandas do capital.

Logo então, surge por parte dos dirigentes políticos e elites intelectuais, a necessidade de se unir para debater propostas que tornassem possível a expansão e as reformas no sistema educacional brasileiro, de maneira que essas reformas caminhassem paralelamente aos estágios de desenvolvimento econômico da sociedade e promovessem o aumento da mão de obra qualificada sob a ótica instrumentalista e prag- 
mática (FRIGOTTO, 2003). As reformas educacionais, surgidas a partir das demandas frisadas pelo teórico, continuaram por evidenciar as diferenças na educação, corroborando com a separação das escolas de ensino profissional para a classe trabalhadora e escolas de ensino acadêmico para classe dominante, por meio de currículos escolares que distinguiam a formação intelectual da formação para o trabalho manual.

Para isso, destacamos que as medidas governamentais na década de 1940 se propuseram a reformar e padronizar o sistema nacional de educação, o que foi levado a efeito com a Reforma Capanema no ano de 1942, sob a promulgação das Leis Orgânicas, que envolviam os seguintes ramos do ensino: secundário, industrial, comercial, agrícola, normal e primário. Nas leis, constatamos que a duas formas de ensino foram colocados em posições opostas e passaram a se articular de maneira insignificante. Sobre tal aspecto Kuenzer (2001) afirma que, nas Leis Orgânicas de Ensino, a formação era específica para uma determinada área de trabalho, ou seja, nos currículos desses cursos não se faziam presentes disciplinas acadêmicas que representavam os saberes necessários para o ingresso ao nível superior. Portanto, se encontravam desarticulados do conhecimento emancipador.

Ainda sobre essa conjectura e sem se desprender da lógica dualista, no período da Reforma Capanema foram criadas as primeiras estruturas do que seria denominado de "Sistema S", iniciando com o Senai (1942) e depois o Senac (1946), configurando um sistema privado de educação profissional que, com o apoio da iniciativa pública, objetivava suprir as necessidades oriundas do capital. Esse fato comprova mais uma vez o interesse do Estado em fortalecer uma educação que priorizava a ocupação profissional do trabalhador, com características de adestramento ou treinamento, em consonância com a Constituição de 1937.

Cabe ressaltar que essa expansão fundamentada pelo crescimento da economia, se deu de maneira desorganizada, a julgar inicialmente pelo cenário de transformações e instabilidades no modo de produção social, advindas da expansão do setor terciário urbano, da constituição do proletariado e da burguesia industrial. Essas mudanças se faziam por meio dos ideários de produção taylorista/fordista, nos quais eram ressaltados os pressupostos de uma formação tecnicista restrita, que, conforme Kuenzer (2007, p. 1156) atendia "[...] às necessidades de um processo produtivo que se caracterizava pela fragmentação, pela estabilidade e pela transparência das tecnologias, predominantemente 
de base eletromecânica", que não exigia um trabalho intelectual significativo dos trabalhadores.

De tal fato, houve o fortalecimento do ensino privado e a dualidade estrutural na educação numa perspectiva de valorização do capital e de aprofundamento da relação entre estado e economia. A partir desse contexto, surgiram críticas sobre as propostas educacionais do país por não suprirem as demandas reais advindas do processo de desenvolvimento econômico, tornando imprescindível a criação de um espaço de debates entre os setores ligados ao sistema educacional no envolto da relação economia/educação. Na essência, essas discussões traziam à tona a defesa por uma formação profissional não mais meramente tecnicista, mas sim voltada para apreensão de conhecimentos necessários na atuação cidadã no mundo do trabalho modificado pela Revolução Científico Tecnológica.

De acordo com Kuenzer (2007), essas discussões foram basilares na promulgação da primeira Lei de Diretrizes e Bases da Educação (LDB), Lei $n^{\circ} 4024$, de 1961, em que constava pela primeira vez de maneira objetiva, a equivalência entre as escolas propedêuticas e profissionais, reconhecendo, "[...] a integração completa do ensino profissional ao sistema regular de ensino, estabelecendo-se plena equivalência entre os cursos profissionais e propedêuticos, para fins de prosseguimento nos estudos" (p. 29).

Pelo modelo educacional descrito na lei, presenciamos a equivalência entre os cursos acadêmicos e profissionalizantes de mesmo nível. Porém, mesmo diante da proposta de convergência entre os saberes humanísticos clássicos e profissionalizantes presente na LDB de 1961 (BRASIL, 1961), os currículos dos cursos profissionais não se desvincularam das demandas do setor produtivo, limitando o conhecimento do aluno que estava matriculado nessa modalidade de ensino e dificultando o seu ingresso na educação superior.

Dessa maneira, seguimos até o ano de 1971 quando, por um preceito ideológico da Teoria do Capital Humano, foi feita a reforma da educação básica pela Lei no 5.692/71 (BRASIL, 1971), que além de fortalecer aspectos inerentes a dualidade na educação do Brasil, atribuiu o caráter compulsório e predominantemente tecnicista no ensino profissionalizante de nível médio. Essa reforma foi justificada pela necessidade de preparar mão de obra para atender as demandas da nova fase de desenvolvimento nacional, conhecido como "milagre brasileiro", além da possibilidade de inserção no mercado de trabalho dos jovens que 
não ingressaram no ensino superior, após a conclusão do $2^{\circ}$ grau. Ramos (2014, p.32) afirma que "Esse é o período em que a Teoria do Capital Humano é mais difundida e que tomam força os princípios da economia da educação".

Com um olhar mais profundo e crítico sobre os verdadeiros motivos que levaram à promulgação da Lei no 5.692, de 1971 (BRASIL, 1971), verificamos que outro aspecto, amarrado a esse discurso sobre necessidade de mão de obra qualificada e da oportunidade de desenvolvimento econômico do aluno que não conseguiu entrar no ensino superior, trata-se do acirramento da disputa de classes, que se tornou evidente dada à crescente procura das camadas populares por um maior nível de escolarização (RAMOS, 2014), fazendo com que o governo agisse no intuito de reduzir a pressão pelo aumento de vagas no ensino superior, além de conter o acesso dos filhos da classe trabalhadora a esse nível de ensino.

Por essa conjuntura, na Lei n 5.692/71 a formação técnica específica se dava com base no princípio educativo do segundo grau, ao passo que se firmavam na lei em questão, os aspectos referentes à Teoria do Capital Humano, apontando para uma relação direta existente entre o aumento da renda e melhor qualificação para o desempenho de funções no trabalho. Nesse viés, identificamos no escopo dessa lei a concepção de que uma maior escolarização influi no avanço da qualidade de vida dos indivíduos, sendo o indivíduo responsabilizado pela sua condição social, uma vez que esta é proporcional ao investimento de que cada um.

Sob os princípios da Teoria do Capital Humano - TCH, os trabaIhadores são considerados proprietários da sua força de trabalho, o que os transforma em capitalistas, que para se manter no mercado devem investir individualmente na qualificação da sua própria força produtiva. Dessa forma, o trabalhador tem maiores condições de competitividade na venda da sua mão-de-obra. Viana e Lima (2010, p. 139), tendo como referência Schultz (1964), afirmam que a ideia era de que "De acordo com a qualificação e o aperfeiçoamento da população, advindos do investimento em educação, elevariam a produtividade dos trabalhadores e os lucros dos capitalistas, impactando na economia como um todo". Com a TCH se justifica as diferenças econômicas e sociais entre países e entre pessoas pelo nível educacional, pois há uma ampliação da produtividade, considerando-se como resultado do investimento em capital humano. 
Segundo Viana e Lima (2010, p.141), a ideia do teórico era de que a educação era um bom investimento visto que, "[...] enquanto o nível de bens de produção tem declinado em relação à renda, o capital humano tem aumentado". Como reflexo dessa teoria, as ideais de preparação para uma profissão impressas na reforma da educação básica, aprovada pela Lei no 5.692/71 (BRASIL, 1971), incitaram a resistência de diferentes segmentos sociais, principalmente daqueles em que a formação se dava nas escolas que preparavam os alunos para o ensino superior. Além disso, a reforma foi "simplesmente descartada (com raras exceções) pela rede privada devido ao seu elevado custo" (GERMANO, 2005, p. 187). A falta de recursos humanos, materiais e a falta de atenção com a formação geral dos estudantes também representam entraves na implantação exitosa dessa reforma.

Adiante, somado à crise do modelo econômico que travou o desenvolvimento científico e tecnológico nacional, no ano de 1982, a Lei no 5.692/71 (BRASIL, 1971) foi alterada pela Lei no 7.044/82 (BRASIL, 1982) no que se refere a profissionalização do ensino de $2^{\circ} \mathrm{grau}$, admitindo novamente a existência de cursos de nível médio eminentemente propedêuticos para os que queriam prosseguir com os estudos e, principalmente, em atendimento à rede privada. Contudo, após as alterações permitidas pela Lei, presenciamos um período esvaziado de mudanças no sistema educacional até 1985 , momento em que, com o fim da Regime Militar, foi possível uma maior abertura política no Brasil, na qual o governo passa a manifestar mais interesse por questões relacionadas às classes populares e, por sua vez, aproxima setores que antes se encontravam à margem das decisões políticas no Brasil, culminando com a promulgação da Constituição Federal aprovada em 1988, que se refere no Art. 205, de forma geral, à educação "como direito de todos e dever do Estado e da família" (BRASIL, 1988).

Na Constituição Federal (BRASIL, 1988), a educação profissional não é mencionada com destaque específico, apenas pontualmente em alguns dos seus artigos. Porém, frente aos seus pressupostos, iniciam-se as discussões para organização de um projeto educacional, basilar na publicação da nova Lei de Diretrizes e Bases da Educação Nacional, a Lei n 9.394, de 1996 (BRASIL, 1996), em que foi considerada, de maneira mais concreta, a necessidade de superar a dualidade estrutural da educação e, ainda, conforme Kuenzer (2007), de atender igualmente às demandas de acesso ao trabalho e a continuidade de estudos, através de uma ampla formação. Entretanto, 
antes de engendrar pela tangibilidade desses princípios identificados pela autora no texto da LDB de 1996, é imprescindível entender sobre o enredo que levou à promulgação desse importante documento.

De início, apontamos para o fato de que a década de 1990 foi marcada por medidas políticas e econômicas que visavam superar a crise do capital manifestada nos anos anteriores, buscando a consolidação do país no mercado internacional, apoiada nos ideais do neoliberalismo e no discurso da globalização. Sendo assim, para o restabelecimento econômico do Brasil, foi necessário ceder ao conjunto de diretrizes internacionais anunciadas pelo Consenso de Washington, que, de acordo com Caires e Oliveira (2016, p. 97), "[...] engendrou uma série de medidas que promoveram um grande ajuste econômico, traduzido em privatizações e na abertura das economias nacionais ao mercado e à competição internacionais [...]", de acordo com as recomendações do Fundo Monetário Internacional - FMl e do Banco Mundial (BIRD), como caminho para o desenvolvimento econômico.

Tendo em vista esse alinhamento das instituições à nova lógica mercantil da economia globalizada, buscou-se a reestruturação produtiva através do processo de modernização da infraestrutura e das mudanças tecnológicas e organizacionais pautadas nos ideários da produção flexível, segundo Harvey (2006). Assim, essas mudanças recaem consequentemente sobre o ensino profissional, uma vez que "esse novo cenário político econômico introduziu no debate educacional a necessidade de formar novos trabalhadores mais flexíveis ou polivalentes, necessários para o novo sistema produtivo" (PIZZI, 2001, p. 109), ou seja, demandando por uma formação que priorizava novas competências e habilidades, fazendo da educação interlocutora na incorporação do Brasil na economia mundial, fomentando os critérios de competitividade e empregabilidade.

Dessa passagem, inferimos sobre os fundamentos da pedagogia das competências que, segundo Silva e Guedes (2018, p. 116), se configura a partir de um paradigma de base não crítica, voltado ao"[...] aprender a ser empregável e a empreender", com a proposição de um trabalhador flexível, com iniciativa, que seja adaptável e criativo, "[...] alinhado ao movimento de revitalização da TCH". A Teoria do capital humano passa, portanto, por uma revitalização, sendo atribuída a capacidade de empregabilidade e de empreendedorismo ao investimento individual do trabalhador em educação, justificando a não inserção no mercado de 
trabalho como consequência da ausência de formação permanente e das condições de adaptabilidade.

Assim, "o processo educativo é reduzido à função de desenvolver habilidades intelectuais, atitudes e conhecimentos que gerarão capacitações para o trabalho e, por consequência, maior produção" (SILVA, 2011, p. 97). Nesse viés, a qualificação profissional, que antes representava o desenvolvimento da capacidade de executar com agilidade e precisão atividades fracionadas, passa a se fundamentar na preparação para o trabalho engatada a um sistema produtivo que exigia desse profissional múltiplas competências, contemplando as ações de pensar e executar. Segundo Ramos (2005, p.112), "[...] a função da escola estaria em proporcionar aos educandos o desenvolvimento de competências genéricas e flexíveis adaptáveis à instabilidade da vida, e não mais o acesso aos conhecimentos sistematizados".

A educação profissional e tecnológica (EPT) começa a ganhar destaque na esfera de discussões legais sobre a formação do trabalhador no país, sendo apresentada na Lei de Diretrizes e Bases da Educação Nacional (LDB), Lei no 9.394/96, disposto no art. 39 (BRASIL,1996), como uma modalidade educacional voltada para o "desenvolvimento de aptidões para a vida produtiva", trazendo como uma das suas finalidades, disposta no art. 35, inciso IV, "a compreensão dos fundamentos científico-tecnológicos dos processos produtivos, relacionando a teoria com a prática, no ensino de cada disciplina" . Também são indicadas algumas possibilidades de organização da educação profissional, quando no art. 39 , discorre sobre a integração com as diferentes formas de educação e a "articulação com o ensino regular ou por meio de diferentes estratégias de educação continuada, em instituições especializadas ou no ambiente de trabalho", conforme o art. 40. Nesse momento, conforme o parágrafo Il do art. 36 é retomada a possibilidade de preparação para "o exercício de profissões técnicas" aos estudantes do ensino médio, garantindo a sua formação geral. (BRASIL,1996).

Porém, no âmbito da EPT, o texto da LDB/1996 não apresentava com clareza os critérios que assegurassem as determinações previstas sobre essa modalidade de ensino, demonstrando a fragilidade existente na relação entre educação e trabalho, tornando inevitável o rompimento com os pressupostos iniciais da referida lei no que diz respeito à superação da dualidade na educação e da ampla formação. Saviani (2000, p. 216), sobre o capítulo da LDB que contempla a Educação Profissional, 
diz que "[...] parece mais uma carta de intenções do que um documento legal, já que não define instâncias, competências e responsabilidades". Portanto, existiam brechas que permitiram várias modificações no texto original da LDB de 1996, se confirmando por medidas educacionais que, consoante ao pensamento de Caires e Oliveira (2016), priorizaram um ensino profissional voltado para a capacitação de trabalhadores com possibilidade de adaptação às necessidade do capital de maior competitividade nos mercados globais, formação fragmentada, de caráter flexível e que impossibilitasse os trabalhadores o acesso ao nível superior.

Tomando como referência os estreitos direcionamentos demandados pelo capital, numa perspectiva restrita e instrumental sobre os objetivos da educação, aos olhos do governo, a LDB de 1996 se torna ineficaz, sendo alterado pelo Decreto no 2.208, de 17 de abril de 1997 (BRASIL, 1997), que instaurou a Reforma do Ensino Técnico, impedindo a oferta do Ensino Profissional integrado ao Ensino Médio, ou seja, tratava dos cursos técnicos com currículo próprio de modo independente do ensino médio, sendo estes ofertados somente nas modalidades concomitante ou subsequente.

O referido decreto, pautado na ideologia de modernização e democratização da educação básica de qualidade para todos, se apresentou como obstáculo na concretização do ensino propedêutico e profissionalizante em currículo único. Para Frigotto, Ciavatta e Ramos (2005, p. 25), o documento "[...] vem não somente proibir a pretendida formação integrada, mas regulamentar formas fragmentadas e aligeiradas de educação profissional em função das alegadas necessidades do mercado", promovendo equivocadamente no indivíduo o desenvolvimento de competências meramente instrumentais e tecnicistas.

Em virtude dessas determinações, Caires e Oliveira (2016, p.116) declaram que o Decreto n 2.208/1997 (BRASIL, 1997) sofreu várias críticas por "[...] Descaracterizar a Educação Tecnológica desenvolvida nas instituições da Rede Federal; promover uma organização curricular baseada em módulos e focada no ensino por competências", além de atender apenas ao mercado e ao setor produtivo, afastando a administração pública do custeio da Educação Profissional e inviabilizando a integração entre Ensino Médio/Educação Profissional, resgatando a dualidade estrutural. Esses pontos continuaram a ser retratados em documentos posteriores como, por exemplo, o Plano Nacional de Educação - PNE 2001-2010, que definiu por metas para educação profissional o uso de 
estratégias para aumentar a oferta de cursos profissionalizantes básicos e de formação técnica de nível médio, além de garantir uma educação profissional permanentemente para o cidadão em idade produtiva e que precisasse se readaptar às novas exigências do mercado de trabaIho (BRASIL, 2001), atribuindo ao próprio cidadão a incumbência do seu preparo para entrar/permanecer no mercado de trabalho.

No caminho contrário a essas medidas, considerando o aumento das críticas feitas a um ensino profissional tecnicista e incoerente com as novas tecnologias do sistema de produção, iniciou-se um período de importantes transformações no cenário educacional do país, em específico na EPT, quando ocorreu a revogação do Decreto no 2.208/97, substituído pelo Decreto no 5.154, de 23 de julho de 2004 (BRASIL, 2004). No subtópico a seguir, direcionamos a discussão proposta para a compreensão dos aspectos fundamentais referentes a essas transformações numa perspectiva relacional com a criação dos cursos técnicos integrados dos IFES, abordando sobre princípios constitutivos desse projeto e as finalidades educacionais.

\section{O projeto de integração dos cursos dos IFES}

Marcando o início do projeto de governo que, em síntese, buscava a democratização do acesso à educação e propunha novos direcionamentos para educação profissional, ainda em 2003, foram organizados pelo MEC dois seminários que tinham como principal objetivo debater sobre as tensas relações entre o universo do trabalho e da educação, além de fazer o resgate dos principais aspectos que vinculam a EPT aos processos educativos, amparados nas concepções de Educação Politécnica e Tecnológica, presentes na atual LDB (BRASIL, 1996).

Portanto, no intuito de acompanhar o andamento das propostas e posições provenientes dos seminários ora desenvolvidos, foi criado, no dia 04 de dezembro de 2003, o Fórum Nacional de Educação Profissional e Tecnológica, por meio da portaria MEC no 3.621, articulado com a sociedade civil e demais participantes das decisões nesse âmbito, que trouxe como resultado a publicação das diretrizes alusivas à essa modalidade educacional (BRASIL, 2004), com os princípios norteadores das práticas para EPT, dentre os quais explicitamos a articulação com a educação básica e a integração ao mundo do trabalho, dada a impor- 
tância de atender às demandas não mais apenas do mercado de trabalho, mas da própria sociedade contemporânea. Fortalecendo, pois, a necessidade de se constituir um ensino profissional que contemplasse o trabalho como princípio educativo, envolvendo as diversas dimensões que se abraçavam a esse princípio: o trabalho, a tecnologia, a ciência, a cidadania e a cultura.

Baseado nessas asserções, em 23 de julho de 2004, é promulgado o Decreto de $n^{\circ} 5.154 / 04$, substituindo o Decreto n० 2.208/97, que estrutura a educação profissional e tecnológica, confirmando a possibilidade de oferta da formação para o trabalho nas formas concomitante ou subsequente ao ensino médio, porém retomando a possibilidade de articulação do ensino médio com a formação para o trabalho por meio da oferta denominada "integrada", em cursos planejados de modo a conduzir o aluno à habilitação profissional técnica de nível médio, na mesma instituição de ensino (BRASIL, 2004).

Em continuidade ao processo de fortalecimento da educação profissional e tecnológica, em 2008, através da Resolução CNE/CEB nº 3, de 9 de julho de 2008, foi implementado o Catálogo Nacional para os Cursos Técnicos, com a organização dos Cursos Técnicos em 12 eixos tecnológicos e apresentando 185 possibilidades de formação técnica (BRASIL, 2008a). Nesse mesmo ano de 2008, por meio da Lei no 11.741 , de 16 de julho (BRASIL, 2008b), a EPT foi incluída na LDB/1996, Capítulo II, Seção IV-A, intitulada "Da Educação Profissional Técnica de Nível Médio" que, dentre outros aspectos, passou a contemplar a oferta dessa modalidade de ensino na forma integrada ao Ensino Médio.

Coeso ao exposto, ainda em 2008, foi promulgada a Lei n. 11.892, de 29 de dezembro, que instituiu a Rede Federal de Educação Profissional, Científica e Tecnológica (RFEPCT), permitindo o reordenamento das Instituições Federais de Educação Tecnológica existentes no país e criando os Institutos Federais de Educação, Ciência e Tecnologia (IFES), conforme Seção II, art. 6, com a finalidade da oferta de "[...] educação profissional e tecnológica, em todos os seus níveis e modalidades, formando e qualificando cidadãos com vistas na atuação profissional nos diversos setores da economia, com ênfase no desenvolvimento socioeconômico local, regional e nacional" (BRASIL, 2008c).

No que se refere aos IFES em específico, a lei descreve em seu inciso I do caput do art. 7 (BRASIL, 2008c), como um dos objetivos dessas instituições, o de ofertar a educação profissional e tecnológica, priorita- 
riamente, na forma integrada, para o público da educação de jovens e adultos (EJA), como também para os concluintes do Ensino Fundamental (ensino médio integrado). Ademais, Pacheco (2015, p. 14) aponta como objetivos do projeto de integração dos cursos dos IFES, a partir da sua compreensão histórica e ontológica, a agregação da formação acadêmica com a preparação para o trabalho e a discussão dos "[...] princípios das tecnologias a ele concernentes dão luz a elementos essenciais para a definição de um propósito específico para a estrutura curricular da educação profissional e tecnológica". Dessa forma, para o teórico, há a proposição de uma formação contextualizada e o sentido real da integração considera toda uma estrutura construída dentro de um contexto de complexidade e que caracteriza a existência humana, tornando possível a formação integral do cidadão.

Frente a esses argumentos que revelam a gênese da educação técnica integrada ao ensino médio, identificamos que os princípios fundamentais dessa modalidade de ensino, emergem de um modelo de educação socialista, na medida em que, conforme Ciavatta e Ramos (2011), essa proposta surge por meio da disseminação das ideias contidas no programa marxiano de educação e nos estudos de Gramsci. Dentre tais ideias, encontramos concepção de um projeto educacional societário revolucionário ligado aos conceitos de escola unitária, educação tecnológica e politécnica e de formação omnilateral do sujeito.

Sendo assim, no desígnio de compreender a convergências entre os conceitos ora mencionados, abordamos inicialmente sobre os fundamentos da Escola Unitária, que é caracterizada por Gramsci (1988, p. 118) como

[..] uma escola única inicial de cultura geral, humanista, formativa, que equilibre equanimemente o desenvolvimento da capacidade de trabalhar manualmente (tecnicamente, industrialmente) e o desenvolvimento das capacidades de trabalho intelectual.

Os princípios da escola unitária são associados aos princípios da integração, pela defesa de uma escola única, que garanta a todos os cidadãos, sem distinção, as mesmas condições de alcance do conhecimento, da cultura e do desenvolvimento profissional, ao defender o equilíbrio entre a formação técnica e a formação intelectual, destacando o trabalho como princípio educativo. 
Diante dessa relação dialética entre educação e trabalho como base em que se assenta a estrutura do ensino integrado, destacamos o conceito de educação tecnológica e politécnica referente à compreensão dos fundamentos da profissão não somente pelo viés técnico, como também pelo científico, tecnológico e sócio-histórico da produção. Para tanto, nos reportamos à Saviani (2007) que, nesta proposta, descreve o ensino médio como a etapa em que se concentra uma

[...] formação necessária para todos, independentemente do tipo de ocupação que cada um venha a exercer na sociedade. Sobre a base da relação explícita entre trabalho e educação desenvolve-se, portanto, uma escola média de formação geral. (p. 159)

A partir das considerações de Saviani (2007), concebemos que o projeto dos cursos técnicos integrados dos IFES, não se satisfaz com o domínio dos aspectos básicos e gerais dos conhecimentos, mas sim pela apreensão de como se dá a articulação entre os saberes teóricos e práticos da ciência e como o saber resultante dessa articulação se materializa no processo produtivo; conduzindo o ensino numa ação educativa de conscientização do sujeito, para agir de maneira autônoma diante da produção dos bens materiais, superando o modelo de ensino médio profissionalizante tecnicista de caráter compulsório proposto dos anos de 1970 a 1990.

Abraçado aos demais conceitos, expomos o de formação omnileral, definida por Gramsci (2001) como uma formação que prioriza a união entre ensino e trabalho na perspectiva de emancipação humana, sabendo que o trabalho, enquanto princípio educativo, se efetiva como atividade de transformação e de realização do ser, elevando o indivíduo a "um certo grau de maturidade e capacidade para a criação intelectual e prática e a uma certa autonomia na orientação e na iniciativa" (p. 36), contrária à formação unilateral provocada pelo trabalho alienado e sua divisão social imposta pelas relações burguesas.

A formação omnilateral se opõe às limitações formativas determinada pelo sistema capitalista e que fomenta a alienação do sujeito. Segundo Frigotto e Ciavatta (2012, p. 265), essa proposta formativa “[...] busca levar em conta todas as dimensões que constituem a especificidade do ser humano e as condições objetivas e subjetivas reais para seu pleno desenvolvimento histórico". Significa, portanto, formar o indivíduo no sentido ontológico, considerando que nas relações em que o trabaIho se desenvolve, o aluno também se forma como ser humano, fazen- 
do da educação o caminho da mudança social almejada, como também instrumento para fortalecimento de um projeto societário e educacional contra-hegemônico no Brasil. Sobre esse aspecto, Moura (2013, p. 715) ressalta ser preciso

[...] um tipo de ensino médio que garanta uma base unitária para todos, fundamentado na concepção de formação humana integral, omnilateral ou politécnica, tendo como eixo estruturante o trabalho, a ciência, a tecnologia e a cultura.

Além disso, garantida essa base, exige também proporcionar o EMI como uma opção, alicerçado aos princípios até aqui discutidos que possibilitam uma educação unitária, não discriminatória, sob a ótica da omnilateralidade.

Entretanto, a materialização do EMI no país, passou a enfrentar dificuldades de várias ordens, sendo a mais pertinente, a falta de um posicionamento político por parte do governo diante de medidas educacionais que fomentam a formação ampla do sujeito, "[...] uma vez que esse tipo de formação claramente não Ihe interessa". (MOURA, 2013, p. 717) considerando, nesse contexto, a predominância do pensamento neoliberal, que concebem a desigualdade social fator favorável ao desenvolvimento do capitalismo.

Diante desse cenário de disputas e contradições, em 2012, por meio da Resolução CNE/CEB № 6, de 20 de setembro, são definidas as Diretrizes Curriculares Nacionais para a Educação Profissional Técnica de Nível Médio, que em suma, trazem os direcionamentos para a construção de currículos concebidos através do trabalho como princípio educativo, possibilitando a definição dos seus objetivos, conteúdos e métodos, o desenvolvimento de metodologias de ensino.

Porém, não obstante as determinações da realidade concreta, Moura (2013, p. 718) infere que essas diretrizes "[...] reiteram uma concepção de formação humana instrumental e utilitária", sua afirmação tem por base as características presentes na Educação Profissional Técnica de Nível Médio proposta pelas diretrizes: centralidade nas competências, submissão à lógica do mercado de trabalho, ênfase nas certificações parciais modular com saídas intermediárias e a priorização das formas subsequente/concomitante ao ensino médio em detrimento da integração, como resultado da submissão ao modo de produção capitalista. 
Contudo, não obstante esse atrelamento aos interesses do capital, continuamos a travessia cronológica das mudanças acontecidas no sistema educacional, nos direcionando ao ano de 2016, quando o governo por meio de uma Medida Provisória (MP 746/2016) altera vários artigos da Lei de diretrizes e Bases da Educação Nacional (LDB), a fim de reformar o ensino médio no país. Após tramitação no Congresso Nacional, a MP se tornou lei em fevereiro de 2017, Lei no 13.415/17 (BRASIL, 2017), alterando a LDB no 9.394 (BRASIL,1996), consolidando a mais recente reforma do ensino médio na legislação educacional do país. Nesse viés, buscamos a seguir, descrever a relação existente entre essa reforma e a proposta de formação dos cursos integrados dos IFES.

\section{A reforma do ensino médio sob a ótica do projeto de integração dos IFES}

A proposta central da atual reforma do ensino médio visa modificar a estrutura desse nível de ensino, contemplando a Base Nacional Comum Curricular - BNCC e os itinerários formativos. No que diz respeito à BNCC, se configura no espaço de definições alusivas aos direitos e objetivos de aprendizagem do ensino médio, em consonância com as diretrizes do Conselho Nacional de Educação, com base nas áreas de conhecimento: I - linguagens e suas tecnologias; II - matemática e suas tecnologias; III - ciências da natureza e suas tecnologias; IV- ciências humanas e sociais aplicadas. (BRASIL, 2017).

Ficam definidas as áreas de conhecimento que serão comuns a todo o ensino médio, no entanto, como a carga horária destinada à BNCC não poderá ser superior a mil e oitocentas horas, do total da carga horária do ensino médio, e o ensino médio deverá contemplar 800 horas anuais e duzentos dias letivos, acrescido do fato de que a organização das áreas e das respectivas competências e habilidades deve ser feita de acordo com critérios estabelecidos em cada sistema de ensino, nos leva a inferir que haverá prejuízo na formação dos sujeitos, pois, abre espaço para disputa por espaço entre as diversas áreas de conhecimento, além do itinerário da formação técnica e profissional, no currículo escolar.

Assim, reforma manteve as finalidades do ensino médio no escopo do art. 35, tendo em vista estabelecer a relação entre o conhecimento e a prática de trabalho, não modificando a LDB, que trata das formas 
de oferta da educação profissional técnica de nível médio "articulada com o ensino médio" e "subsequente, em cursos destinados a quem já tenha concluído o ensino médio" (BRASIL, 2017), além disso, não alterou o princípio da articulação entre a Educação Básica com a Educação Profissional, estabelecido pela Lei no 11.892 de 2008 (BRASIL, 2008c) e pela Resolução CNE/CEB n 06/2012 (BRASIL, 2012), mas há espaços para contemplar ambas nos cursos integrais?

Por isso, chamamos a atenção para alguns problemas alusivos ao ensino médio quanto ao equilíbrio na organização curricular entre a BNCC/itinerários formativos e as formas de articulação entre o ensino médio e o ensino técnico, pois, ao tempo em que o ensino técnico poderá se tornar parte de ensino médio, poderá comprometer, de maneira geral, as finalidades desse nível de ensino expressas na LDB (BRASIL, 1996), pela ênfase que pode ser dada em um ou outro itinerário formativo.

Assim, a redução das áreas de conhecimento propostas pela BNCC, impõe como obstáculo a formação ampla do estudante, pois diante da proposta dos cursos integrados dos IFES, essa formação está centrada na apropriação crítica dos conhecimentos científicos e sua relação com o desenvolvimento cultural e o mundo do trabalho, tornando relevante uma maior carga horária de todos os componentes curriculares que compõem a formação humana integral, entre os quais estas se inserem, mas como atender a essas demandas da formação geral e da formação técnica na organização do currículo?

Outro ponto negativo dessa reforma é quando constatamos que, das áreas de conhecimento da BNCC, quatro correspondem aos itinerários formativos, porém o único itinerário que não corresponde a uma das áreas de conhecimento é a formação técnica e profissional. Nessa perspectiva, mais uma vez é fortalecida a dualidade na educação, pois domínio dos fundamentos científicos, teóricos e técnicos dos diversos processos do trabalho, associados às dimensões humanas, não é concebido pela atual reforma como uma possibilidade de formação ampla do sujeito.

\section{Considerações finais}

No decorrer dessa investigação, percebemos que as mudanças históricas no campo educacional do país, de maneira geral, correspon- 
dem apenas a uma parte da transformação maior e muito mais abrangente, que contempla toda a estrutura social brasileira, trazendo sempre como pano de fundo as relações de poder constituídas na sociedade.

Ao tratarmos especificamente do ensino médio e da educação profissional observamos que estes sempre estiveram situados em meio a um campo de intensos conflitos, contradições e interesses, pois as decisões são determinantes na formação do perfil do profissional do país, ficando a cargo da classe dominante direcionar a formação do cidadão, a julgar pelos seus interesses. Sendo assim, considerando os avanços e retrocessos analisados, principalmente por meio de medidas governamentais, afirmamos que sempre foi um desafio construir uma identidade tanto para a última etapa da educação básica, quanto para educação profissional no Brasil.

Desse ponto, evidenciamos ensino médio integrado (EMI), mais precisamente, os cursos técnicos integrados dos Institutos Federais de Educação Ciência e Tecnologia (IFES), que surgem como uma proposta de construção identitária, a partir de uma política educacional, no intuito de ampliar o acesso à educação pública, profissional, científica e tecnológica, se opondo à lógica dominante de formação profissional voltada somente em atender às demandas imediatas do mercado

A ideia de integração dos cursos integrados dos IFES foi concebida a partir dos conceitos de escola unitária, educação politécnica e tecnológica e omnilateralidade, garantindo a todos os cidadãos uma formação ampla pautada na aquisição de bens culturais e históricos, e que não seja um instrumento de dominação ideológica, manipulado pelas classes hegemônicas. No entanto, sob a análise do movimento histórico, percebemos o ensino técnico profissional, sempre foi reforçado como trabalho manipulativo e meramente instrumental, de modo a preparar e qualificar o trabalhador para atender imediatamente os interesses da indústria e do mercado.

Assim, após compreender que o EMI representa profunda mudança desse cenário, tendo em vista sua proposta de romper com a dualidade estrutural, superando a divisão social do trabalho através da articulação entre a educação básica e educação profissional técnica (EPT) inferimos sobre a nova reforma do ensino médio, por meio da Lei no 13.415/17 (BRASIL, 2017), como um retrocesso na luta contra hegemônica no sistema educacional do país. 


\section{Referências}

BRASIL. Decreto n 7566, de 23 de setembro de 1909. Crêa nas capitaes dos Estados da Republica Escolas de Aprendizes Artifices, para o ensino profissional primario e gratuito. Diário Oficial da União: Rio de Janeiro, RJ, p. 6975, 26 set. 1909. Disponível em: http://portal.mec. gov.br/setec/arquivos/pdf3/decreto_7566_1909.pdf. Acesso em: 04 abr. 2018.

BRASIL. Constituição dos Estados Unidos do Brasil, de 10 de novembro de 1937. Leis Constitucionais. Diário Oficial da União: Rio de Janeiro, RJ, 10 nov. 1937 Disponível em: http://www.planalto.gov.br/ccivil_03/ constituicao/constituicao37.htm. Acesso em: 04 abr. 2018.

BRASIL. Lei no 4.024, de 20 de dezembro de 1961. Fixa as Diretrizes e Bases da Educação Nacional. Diário Oficial da União: Brasília, DF, 27 dez. 1961.

BRASIL. Lei no 5.692, de 11 de agosto de 1971. Fixa Diretrizes e Bases para o ensino de $1^{\circ}$ e $2^{\circ}$ graus, e dá outras providências. Diário Oficial da União: Brasília, DF, 12 ago. 1971. Revogada pela Lei no 9.394, de 20 dez. 1996.

BRASIL. Lei no 7.044, de 18 de outubro de 1982. Altera dispositivos da Lei n 5.692, de 11 de agosto de 1971, referentes a profissionalização do ensino de $2^{\circ}$ grau. Diário Oficial da União: Seção 1, Brasília, DF, p.19539, 19 out. 1982.

BRASIL. Constituição da República Federativa do Brasil de 1988. Brasília, DF, 5 out. 1988.

BRASIL. Lei № 9.394, de 20 de dezembro de 1996. Estabelece as diretrizes e bases da educação nacional. Diário Oficial da União: Brasília, DF, 23 dez. 1996.

BRASIL. Decreto n².208, de 17 de abril de 1997. Regulamenta o $\S 2^{\circ}$ do art. 36 e os arts. 39 a 42 da Lei no 9.394, de 20 de dezembro de 1996, que estabelece as diretrizes e bases da educação nacional. Diário Oficial da União: Brasília, DF, 18 abr. 1997. Revogado pelo Decreto n 5.154, de 2004.

BRASIL. Lei n. 10.172, de 9 de janeiro de 2001. Estabelece o Plano Nacional de Educação. Diário Oficial da União: Brasília, DF, 10 jan. 2001. 
BRASIL. Portaria MEC no 3.621, de 04 dez. 2003. Dispõe sobre a criação, atribuições e funcionamento do Fórum Nacional de Educação Profissional e Tecnológica. Diário Oficial da União: Seção I, p.23, 05 dez. 2003.

BRASIL. Decreto $n^{\circ} 5.154$, de 23 de julho de 2004. Regulamenta o $\S 2^{\circ}$ do art. 36 e os arts. 39 a 41 da Lei no 9.394, de 20 de dezembro de 1996, que estabelece as diretrizes e bases da educação nacional, e dá outras providências. Diário Oficial da União: Brasília, DF, 26 jul. 2004.

BRASIL. Resolução n 3, de 9 de julho de 2008. Dispõe sobre a instituição e implantação do Catálogo Nacional de Cursos Técnicos de Nível Médio. Diário Oficial da União: Seção 1, Brasília, p. 9, 10 de julho de 2008a.

BRASIL. Lei $n^{\circ} 11.741$, de 16 de julho de 2008. Altera dispositivos da Lei no 9.394, de 20 de dezembro de 1996, que estabelece as diretrizes e bases da educação nacional, para redimensionar, institucionalizar e integrar as ações da educação profissional técnica de nível médio, da educação de jovens e adultos e da educação profissional e tecnológica. Diário Oficial da União: Brasília, DF, 17 jul. 2008b.

BRASIL. Lei n 11.892, de 29 de dezembro de 2008. Institui a Rede Federal de Educação Profissional, Científica e Tecnológica, cria os Institutos Federais de Educação, Ciência e Tecnologia, e dá outras providências. Diário Oficial da União: Brasília, DF, 30 dez. 2008c.

BRASIL. Resolução no 6, de 20 de setembro de 2012. Define Diretrizes Curriculares Nacionais para a Educação Profissional Técnica de Nível Médio. Diário Oficial da União: Seção 1, Brasília, DF, p. 222012, 21 de setembro de 2012.

BRASIL Lei n¹3.415, de 16 de fevereiro de 2017. Altera as Leis $n \circ 9.394$, de 20 de dezembro de 1996, que estabelece as diretrizes e bases da educação nacional, e 11.494, de 20 de junho 2007, que regulamenta o Fundo de Manutenção e Desenvolvimento da Educação Básica e de Valorização dos Profissionais da Educação, a Consolidação das Leis do Trabalho - CLT, aprovada pelo Decreto-Lei $n^{\circ} 5.452$, de $1^{\circ}$ de maio de 1943, e o Decreto-Lei no 236, de 28 de fevereiro de 1967; revoga a Lei no 11.161, de 5 de agosto de 2005; e institui a Política de Fomento à Implementação de Escolas de Ensino Médio em Tempo Integral. Diário Oficial da União: Brasília, DF, 17 fev. 2017. 
CAIRES, V. G.; OLIVEIRA, M. A. M. Educação Profissional Brasileira: da colônia ao PNE 2014-2024. Petrópolis/RJ: Vozes, 2016.

CIAVATTA, M.; RAMOS, M. Ensino médio e educação profissional no Brasil: dualidade e fragmentação. Retratos da Escola, Brasília, v. 5, n. 8, p. 27-41, jan./jun. 2011.

CUNHA, L. A. Ensino profissional na irradiação do industrialismo. São Paulo: Unesp, 2005.

FRIGOTTO, G. Educação e crise do capitalismo real. 5. ed. São Paulo: Cortez, 2003.

FRIGOTTO, G. Escola e trabalho numa perspectiva histórica: contradições e controvérsias. Revista de Ciências da Educação. Lisboa: [s.n.]. 2009. p. 129-136.

FRIGOTTO, G.; CIAVATTA, M.; RAMOS, M. A gênese do decreto n. 5.154|2004: um debate no contexto da democracia restrita. In: FRIGOTTO, G.; CIAVATTA, M.; RAMOS, M. (org.). Ensino Médio integrado: concepções e contradições. São Paulo: Cortez, 2005.

FRIGOTTO, G.; CIAVATTA, M. Trabalho como princípio educativo. In: SALETE, R.; PEREIRA, I. B.; ALENTEJANO, P.; FRIGOTTO, G. (Org.) Dicionário da educação do campo. São Paulo: Escola Politécnica Joaquim Venâncio, 2012. GERMANO, J.W. Estado militar e educação no Brasil. 4. ed. São Paulo: Cortez, 2005.

GRAMSCl, A. Os intelectuais e a organização da cultura. Rio de Janeiro: Civilização Brasileira, 1988.

GRAMSCl, A. Cadernos do Cárcere. Tradução de Carlos Nelson Coutinho. Vol. 2. 2a edição. Rio de Janeiro: Brasileira, 2001.

HARVEY, D. Condição pós-moderna: uma pesquisa sobre as origens da mudança cultural. 15. ed. São Paulo: Loyola, 2006.

KUENZER, A. Ensino Médio e Profissional: as políticas do Estado neoliberal. São Paulo: Cortez, 2001.

KUENZER, A. (org.). Ensino Médio: construindo uma proposta para os que vivem do trabalho. São Paulo: Cortez, 2007.

MANFREDI, S. M. Educação profissional no Brasil. São Paulo: Cortez, 2002. 
MOURA, D. H. Ensino médio integrado: subsunção aos interesses do capital ou travessia para a formação humana integral? Educação e Pesquisa, vol. 39, núm. 3, 2013, p. 705-720 Universidade de São Paulo, São Paulo, Brasil.

NASCIMENTO, M. N. M. Ensino Médio no Brasil: determinações históricas. Publ. UEPG Ci. Hum., Ci. Soc. Apl., Ling., Letras e Artes, Ponta Grossa, v. 15, n. 1, p. 77-87, 2007.

PACHECO, E. Fundamentos político-pedagógicos dos institutos federais: diretrizes para uma educação profissional e tecnológica transformadora. Natal: IFRN, 2015

PIZZI, L. C. As transformações produtivas e os desafios às propostas pedagógicas progressistas nos anos 90 . Revista Educação. Maceió, ano 9, n. 14, p. 17-31, jul. 2001.

RAMOS, M. Possibilidades e desafios na organização do currículo integrado. In: FRIGOTTO, G.; CIAVATTA, M.; RAMOS, M. (Org.). Ensino médio integrado: concepções e contradições. São Paulo: Cortez, 2005.

RAMOS, M. História e política da educação profissional - Curitiba, v. 5 Coleção formação pedagógica. Instituto Federal do Paraná, 2014.

SAVIANI, D. A nova lei da educação: trajetória, limites e perspectivas. 6. ed. Campinas: Autores Associados, 2000.

SAVIANI, D. Trabalho e educação: fundamentos ontológicos e históricos. Revista Brasileira de Educação. Campinas, v. 12, n. 34, jan./abr., 2007.

SCHULTZ, T. W. O valor econômico da educação. Rio de Janeiro: Zahar Editores, 1964.

SILVA, D. F. F. da. Reflexões sobre educação, escola e mudanças no mundo do trabalho a partir de uma perspectiva crítica. In: LIMA FILHO, D. L. (org.). Trabalho e formação humana: o papel dos intelectuais e da educação. Curitiba: Ed. UTFPR, 2011, p. 85 - 104.

SILVA, M. M.; GUEDES, T. Formação dos trabalhadores para o capital: uma análise de projetos pedagógicos de cursos técnicos subsequentes do IFSC, campus Florianópolis. Educação \& Formação. v 3. n 9, p. 102-120, 2018. 
VIANA, G.; LIMA. J. F. de. Capital humano e crescimento econômico. Interações. Campo Grande, v. 11, n. 2 p. 137-148, jul./dez. 2010

Recebido em: Março/2020

Aceito em: Maio/2020 